\title{
Selective oxidation of tool steel surfaces under a protective gas atmosphere using inductive heat treatment
}

\author{
S. Schöler ${ }^{*}$, D. Yilkiran ${ }^{2}$, D. Wulff, F. Özkaya ${ }^{2}$, K. Möhwald, B.-A. Behrens ${ }^{2}$, H.J. Maier ${ }^{1}$ \\ ${ }^{1}$ Institut für Werkstoffkunde (Materials Science), Leibniz Universität Hannover, 30823 Garbsen, Germany \\ ${ }^{2}$ Institut für Umformtechnik und Umformmaschinen (Forming Technology), Leibniz Universität Hannover, 30823 Garbsen, Germany
}

\begin{abstract}
For the realization of liquid lubricant free forming processes different approaches are conceivable. The priority program 1676 "Dry forming - Sustainable production through dry machining in metal forming" addresses this issue in the context of metal forming processes. The present study reports results from one subproject of the priority program that employs selective oxidization of tool steel surfaces for the implementation of a dry sheet metal deep drawing process. Within the present study, specimen surfaces of the tool steel (1.2379) were heat-treated to optimize their tribological properties with respect to sliding wear behaviour in contact with drawn sheet metal $(\mathrm{DP} 600+\mathrm{Z})$. The heat treatment was designed to result in the formation of selective oxide layers that can act as friction reducing separation layers. The heating setup employed an inductive heating under protective gas atmosphere. Selective oxidation was realized by controlling the residual oxygen content. Specifically, the specimens were heated in the near-surface region just above the annealing temperature, thus avoiding the degradation of mechanical properties in the bulk. Evaluation of hardness along cross-sections of each specimen revealed suitable initial temperatures for the inductive heat treatment. Oxide layer systems were analyzed regarding their tribological sliding wear behaviour after selective oxidation, as well as their morphology and chemical composition before and after the sliding wear tests.
\end{abstract}

Keywords: Dry metal forming, sheet metal forming, tribology

\section{Introduction}

For modern industrial manufacturing, economic and ecological objectives become more and more significant. In this respect, lubricant free dry metal forming is a promising approach and is examined within the scope of the priority program 1676 founded by the German Research Foundation (DFG). However, the sheet metal forming and the bulk metal forming industries are two of the most affected sectors in the context of related manufacturing failures [1-3]. In sheet metal forming, deep drawing processes feature large contact areas between tool surface and sheet metal, and thus, lubricant oils are used to reduce friction and increase tool wear resistance. Lubricants are ecological polluting products which are inconsistent with requirements of sustainable production. Moreover, process chains are extended by additional cleaning processes. Selective oxidation of tool steel surfaces promises sustainability in modern manufacturing. The specific loading case of deep drawing processes is very complex, but depends in general on friction. Yet, the direct contact of the tool surface and the drawn sheet metal should be avoided. Therefore thin oxide layers were generated on the tool steel surfaces using a heat treatment under defined atmospheres.In earlier studies, positive effects of $\alpha-\mathrm{Fe}_{2} \mathrm{O}_{3}$ oxide layers on friction and wear behaviour have already been reported. Lubricant free pin on disc tests at temperatures between $20{ }^{\circ} \mathrm{C}$ and $600{ }^{\circ} \mathrm{C}$ showed that oxidized tool steel had friction-reducing properties. However, $\alpha-\mathrm{Fe}_{2} \mathrm{O}_{3}$ was also generated from metallic debris, so that homogeneous oxide layers could not be realized [4-6].

The present study focuses on the wear behaviour of selectively oxidized tool steel specimens (1.2379), which were heat treated inductively under an argon process atmosphere with an oxygen content of 0.03 vol.- $\%$. These process conditions were selected to favour the formation of $\alpha-\mathrm{Fe}_{2} \mathrm{O}_{3}$ oxide layer systems, which can act as a friction reducing separation layers. The friction coefficients and wear resistance were determined to compare the systems' behaviour with results obtained in previous studies using convective tempering methods.

\footnotetext{
* Corresponding author: schoeler@iw.uni-hannover.de
} 


\section{Experimental}

\subsection{Materials and preparation}

For investigations of sliding wear, cylindrical specimen of the tool steel X153CrMoV12 (EU alloy grade 1.2379) with an elemental composition of $12 \% \mathrm{Cr}, 1.55 \% \mathrm{C}, 0.9 \%$ $\mathrm{V}$ and $0.8 \%$ Mo (in wt.- $\%$ ) were hardened to $56 \pm 2 \mathrm{HRC}$ $((600 \pm 30) \mathrm{HV} 30)$. The specimens were circular ground to generate a surface roughness with an arithmetical mean height value of $S_{\mathrm{A}}=1.04 \mu \mathrm{m} \pm 0.09 \mu \mathrm{m}$, which was measured using a 3D scanning laser microscope (Keyence VK-9710). Prior to the oxidizing heat treatments, contaminations were removed from the specimen surfaces by different cleaning steps in an ultrasonic bath. After the first cleaning step with ethanol (>96\%) for 10 minutes, lipophilic contaminations were removed in a further cleaning step with acetone ( $>99 \%$ ) before cleaning with pure ethanol (> $99.8 \%$ ) to remove hydrophilic contaminations.

Afterwards the specimens were marked at the front to localize positions for subsequent surface analysis of selected areas. The design of the specimen is shown schematically in Fig. 1 and is described in detail in [7].

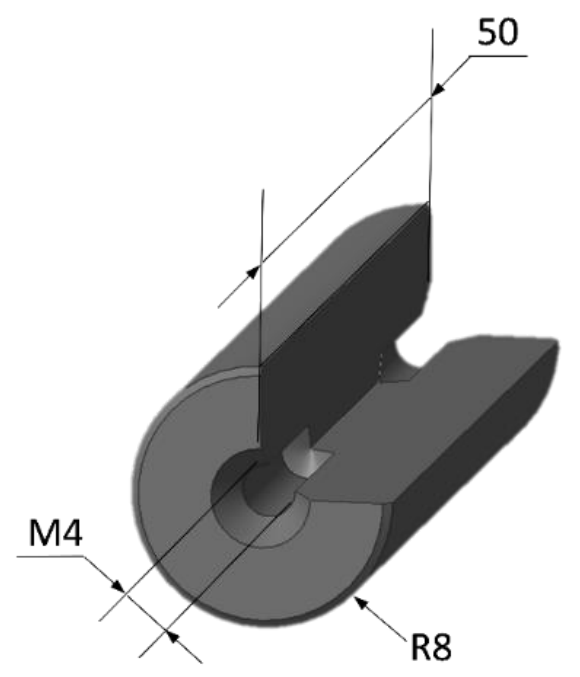

Fig. 1. Planar cross section of the specimen geometry used

The dual-phase-steel DP600+Z (EU alloy grade 1.0936 with an elemental composition of $2.0 \% \mathrm{Mn}, 1.5 \% \mathrm{Si}$, $1.0 \% \mathrm{Cr}+\mathrm{Mo}+\mathrm{Ni}, 0.14 \% \mathrm{C}, 0.07 \% \mathrm{P}, \min .0 .015 \%$ $\mathrm{Al}, 0.015 \% \mathrm{~S}, 0.005 \% \mathrm{~B}$; in wt.- $\%$ ) was used as sheet metal for the wear investigations. The metal strips had a nominal thickness of $0.96 \mathrm{~mm}$ and a width of $35 \mathrm{~mm}$ and were factory-provided hot-dip galvanised with a $\mathrm{Zn}$ coating of $9.5 \mu \mathrm{m} \pm 0.5 \mu \mathrm{m}$ thickness.

\subsection{Selective oxidation}

Selective oxidation of the specimen surfaces was performed in a tubular furnace. Stationary conditions were achieved by controlling the gas flow, the composition of the atmosphere and the process temperature. Argon (Ar) with a purity of $99.996 \%$ was used as inert shielding gas. The heat treatments were conducted inductively with a coupled electrical power of $3000 \mathrm{~W}$ at a frequency of $500 \mathrm{kHz}$. The inductive heat treatment was performed at a constant oxygen content of 0.03 vol.- $\%$ measured by a lambda probe applying different peak temperatures above the annealing temperature $\left(530^{\circ} \mathrm{C}\right)$ of the tool steel at a constant heating rate of $10^{\circ} \mathrm{C} / \mathrm{s}$. After holding the specimen at the selected target temperature for one minute, the temperature was decreased to $500{ }^{\circ} \mathrm{C}$. Subsequently the specimens were hold isothermally for 15 minutes prior to cooling down to ambient temperature at a rate of $5^{\circ} \mathrm{C} / \mathrm{s}$, cf. Fig. 2 .

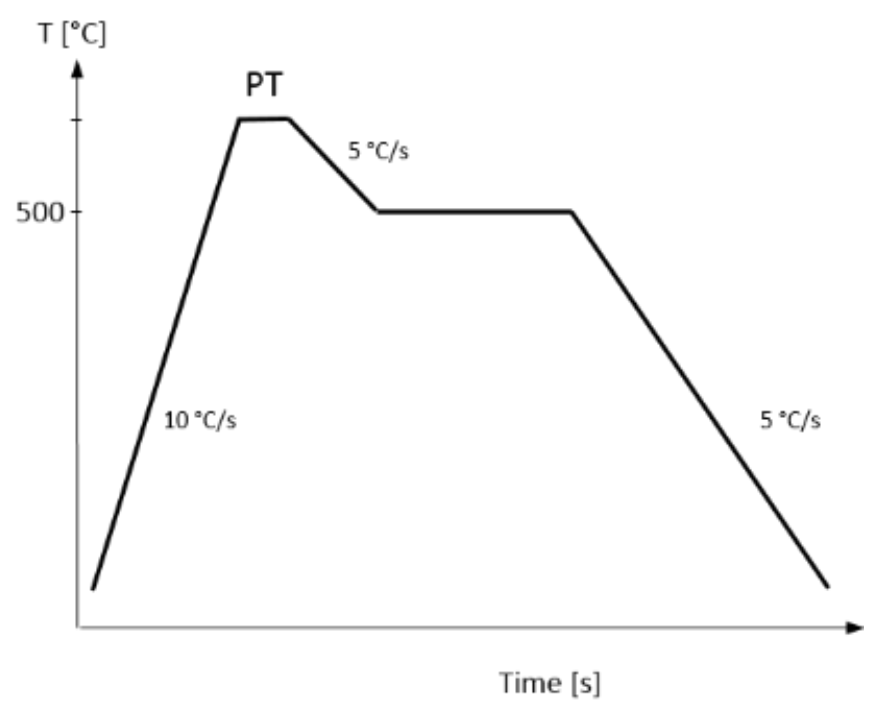

Fig. 2. Schematic showing the temperature-time-regime used for the heat treatments, PT: peak temperature

The actual peak temperatures of the inductive heat treatment are shown in Table 1 along with the parameters used for the convectively tempered specimen. For sake of completeness, the native specimen is included as well.

Table 1. Process parameters of the actual heat treatments used

\begin{tabular}{cccc}
\hline $\begin{array}{c}\text { specimen/ } \\
\text { identifier }\end{array}$ & $\begin{array}{c}\text { duration of isothermal hold/ } \\
\text { peak temperature (PT) }\end{array}$ & $\begin{array}{c}\text { heating } \\
\text { rate }\end{array}$ & $\begin{array}{c}\text { heat } \\
\text { treatment } \\
\text { type }\end{array}$ \\
\hline R1 (native) & $/$ & $/$ & $/$ \\
A1 & $60 \mathrm{~min} / 510^{\circ} \mathrm{C}$ & $5{ }^{\circ} \mathrm{C} / \mathrm{s}$ & convective \\
B1 & $15 \mathrm{~min} / 570^{\circ} \mathrm{C}$ & $10^{\circ} \mathrm{C} / \mathrm{s}$ & inductive \\
B2 & $15 \mathrm{~min} / 620^{\circ} \mathrm{C}$ & $10^{\circ} \mathrm{C} / \mathrm{s}$ & inductive \\
B3 & $15 \mathrm{~min} / 650^{\circ} \mathrm{C}$ & $10^{\circ} \mathrm{C} / \mathrm{s}$ & inductive \\
B4 & $15 \mathrm{~min} / 700^{\circ} \mathrm{C}$ & $10^{\circ} \mathrm{C} / \mathrm{s}$ & inductive
\end{tabular}




\subsection{Measurement of hardness}

After the heat treatment, the hardness of the specimens was measured along cross sectional areas from the edge to the centre, in order to investigate the influence of different peak temperatures on the mechanical properties. The measurements were conducted according to the ISO 6507-1 standard (Metallic materials - Vickers hardness test - Part 1).

\subsection{Strip drawing tests}

Strip drawing tests were carried out in order to determine the friction coefficient $\mu$ of the selectively oxidized specimen surfaces. The tests were performed with $90^{\circ}$ redirection, to reproduce the loading case of deep drawing and related wear investigations. For this purpose, steel strips of DP $600+Z$ were slid over the corresponding specimen surfaces at a drawing speed of $20 \mathrm{~mm} / \mathrm{s}$ with a contact pressure of $18 \mathrm{MPa}$. The strip drawing setup is illustrated schematically in Fig. 3. The friction coefficient $\mu$ was calculated from the measured forces using the equation

$$
\mu=\frac{2}{\pi} \cdot \ln \frac{F_{\mathrm{p}}-F_{\mathrm{b}}}{F_{\mathrm{c}}}
$$

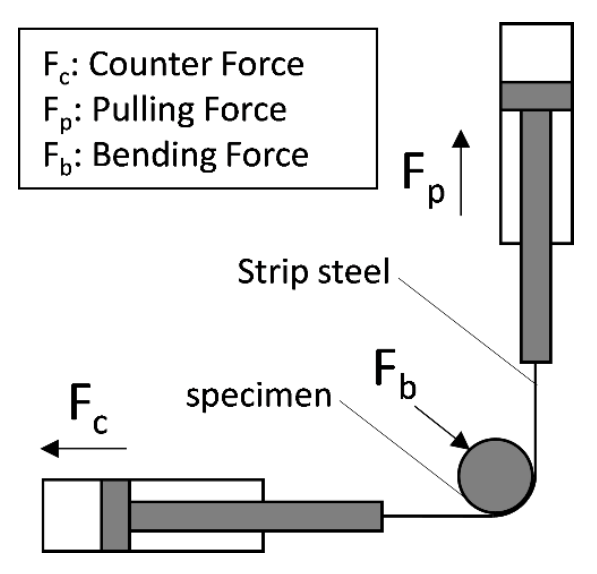

Fig. 3. Schematic of the strip drawing tests

\subsection{Wear investigations}

The wear investigations were carried out at a hydraulic wear test bench to analyze the sliding wear behaviour of the tribological system formed by the wear specimen and the sheet metal. By pulling the sheet metal from a coil over the oxidized specimen with $90^{\circ}$ re-direction, a loading case is generated that resembles the one of modern deep drawing processes. For the investigations, the sheet metal used was provided from a coil, which was cleaned inline to remove the prelube-oil from the surface. A 10\% solution of a cleaning fluid (Tickopur R33) was used. To avoid residues of the cleaning solution especially phosphates - on the surface of the sheet metal, the sheet metal was then cleaned with an ethanol (>96\%) soaked sponge prior to getting in contact with the tool steel specimen. Detailed information of the wear test bench procedure can be found in [8]. The actual setup of the wear test bench is shown in Fig. 4.
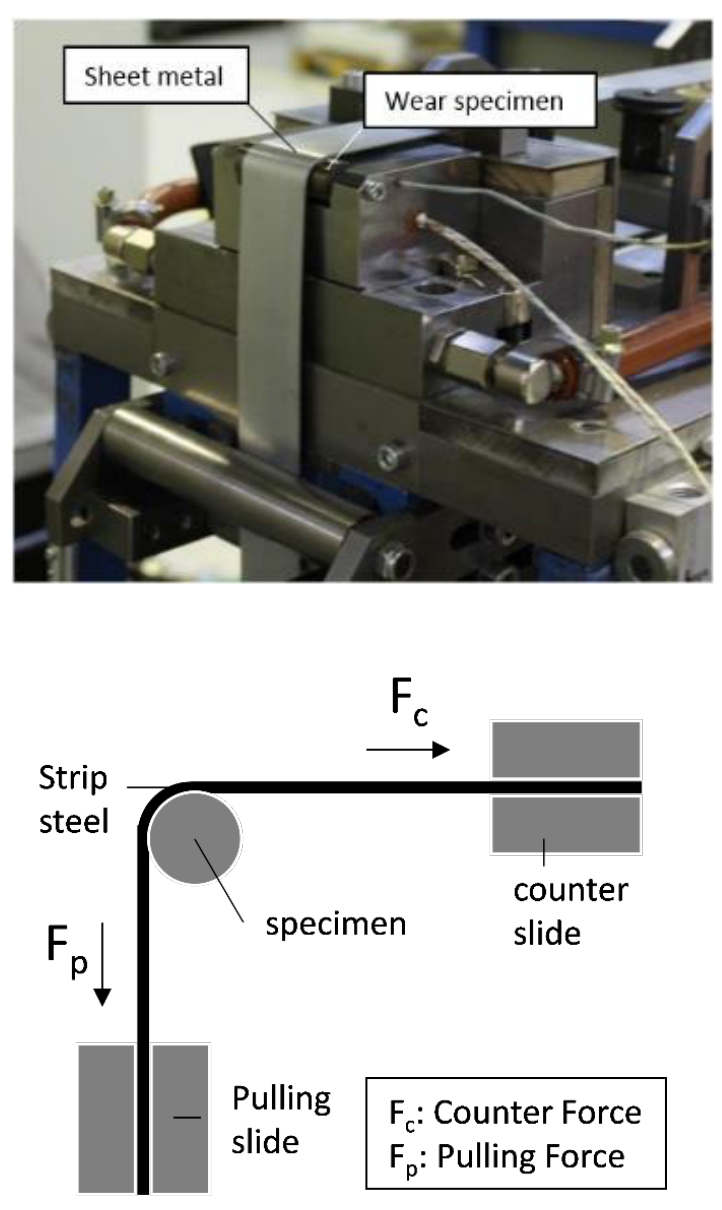

Fig. 4. Wear test bench with $90^{\circ}$ re-direction (top), principle of wear investigations (bottom)

\subsection{Surface analysis}

Different methods were employed to analyze the specimen surface. The specimen were initially characterized regarding their topography using 3D microscopy (Keyence VK-9710). Further investigations were performed using a scanning electron microscope (SEM: Zeiss Supra $55 \mathrm{VP}$ ), which was equipped with different detectors. Inlens and secondary electron detectors were employed prior to energy dispersive X-ray spectroscopy (EDX) to determine the chemical composition of selected areas. EDX data were collected at an acceleration voltage of $3 \mathrm{kV}$ in areas of $90 \mu \mathrm{m}$ x $60 \mu \mathrm{m}$. For representative cases, high resolution cross sections were analyzed using a focussed ion beam SEM (Zeiss Auriga). Low acceleration voltages were used in order to minimize contribution to the signal from the underlying substrate when analyzing the very thin oxide layer systems. 


\section{Results}

\subsection{Oxide layer characterisation}

For comparison with results from previous investigations that had employed convective tempering under defined argon atmospheres $\left(\mathrm{O}_{2}\right.$ content $=0.03$ vol. $\left.-\%\right)$, the surface morphology of the inductively tempered specimen surfaces was characterized in detail. Reference samples (diameter: $12 \mathrm{~mm}$, height: $2 \mathrm{~mm}$ ) of the hardened $(56 \pm 2$ HRC) tool steel (1.2378) used were polished with $3 \mu \mathrm{m}$ diamonds dispersion and inductively tempered under using the conditions of the selective oxidation process of specimen B1, cf. Table 1 .

Secondary electron images of the surface are shown in Fig. 5. The oxide layer exhibit the typical structure of $\alpha$ $\mathrm{Fe}_{2} \mathrm{O}_{3}$ layers, which have been characterized in detail in [8]. The structure of the oxide layer generated seems homogeneous in most regions. However, it is not uniform throughout, and several areas have not been oxidized. The inset in Figure 5 shows a cross section prepared from the marked area using focused ion-beam cutting. The selected area was coated with a platinum layer before sectioning in order to protect the oxide during the process. The oxide layer has an average thickness of about $450 \mathrm{~nm}$, while precipitations can also be detected at the surface that vary in size and are not oxidized. Beneath the oxide layer, a thin reaction zone occurs (dark appearing areas) suggesting a near-surface enrichment of light elements.

The EDX mappings (Fig. 6.) revealed a superposition of iron $(\mathrm{Fe})$ and oxygen $(\mathrm{O})$ in the areas corresponding to the generated oxide layer. The precipitations seen in uncovered regions consisted mainly of chromium $(\mathrm{Cr})$, carbon (C) other alloying components like vanadium (V), which is typical for carbides in this material.

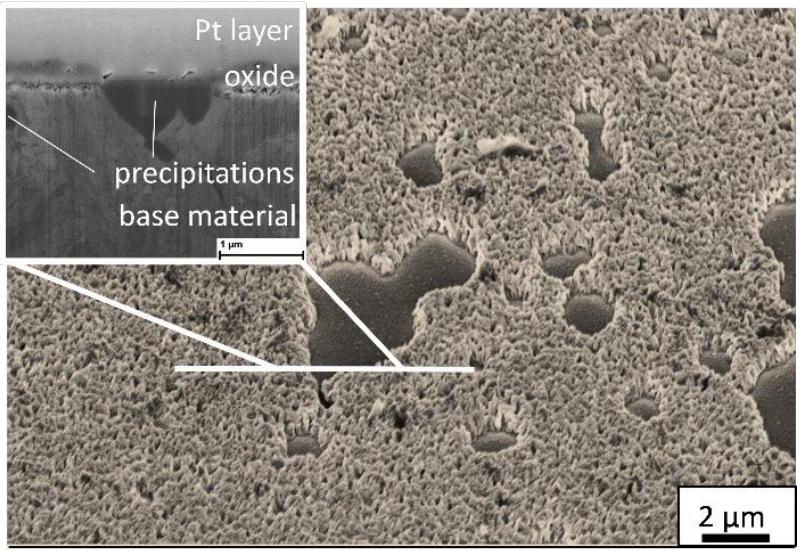

Fig. 5. SEM micrograph of the oxide layer formed after inductive heat treatment with FIB-cut cross sectional secondary electron image shown in the inset

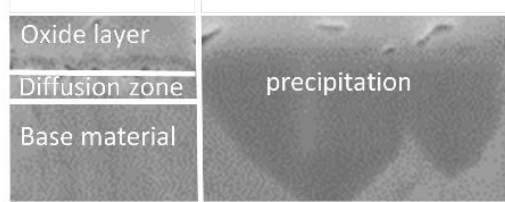

Fe

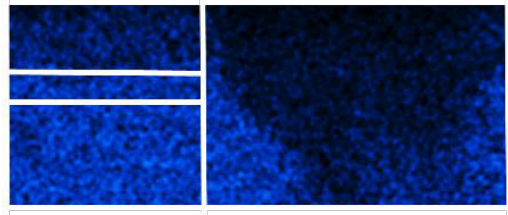

$\mathrm{Pt}$
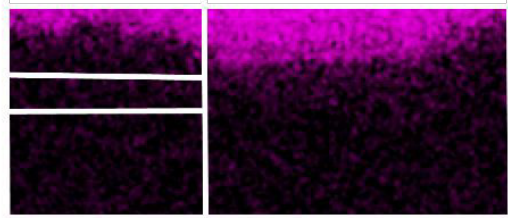

C
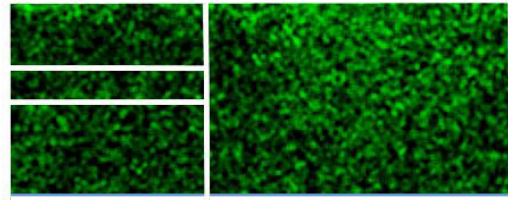

0
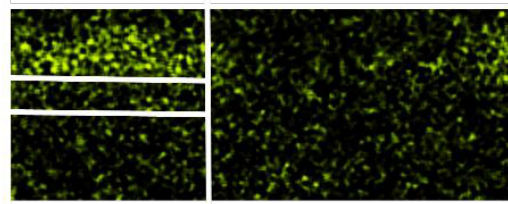

V
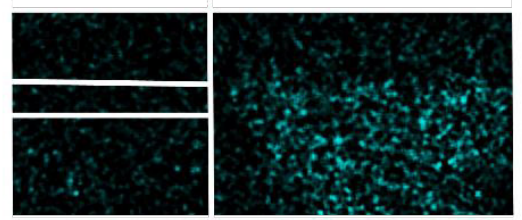

$\mathrm{Cr}$
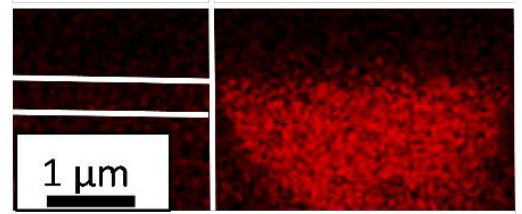

Fig. 6. Secondary electron image of a cross section (top) prepared by focused-ion beam cutting of a reference sample; the corresponding elemental mappings were recorded at $15 \mathrm{keV}$

For comparison, a convectively heat-treated reference sample (diameter: $12 \mathrm{~mm}$, height: $2 \mathrm{~mm}$ ) was characterized. The selective oxidation process was performed using the conditions $\left(510^{\circ} \mathrm{C}\right.$ for 60 minutes) described in detail in [8]. In this case, the oxide formed was also an $\alpha-\mathrm{Fe}_{2} \mathrm{O}_{3}$ layer system. Morphologically, the layer was similar to the layer on the inductively tempered specimen. However, the chain like bondings of the oxide to the substrate had coarsened. This can be attributed to a thin oxide layer, which was detected with an average thickness of about $150 \mathrm{~nm}$ in a cross section using focused ion-beam cutting (Fig. 7, inset). Compared to inductive tempering chromium precipitations were also detected, but in a higher extend preventing the oxide layer to cover the surface at these areas. So, large-scaled areas, which are not covered by the oxide layer can be detected after convective tempering. 


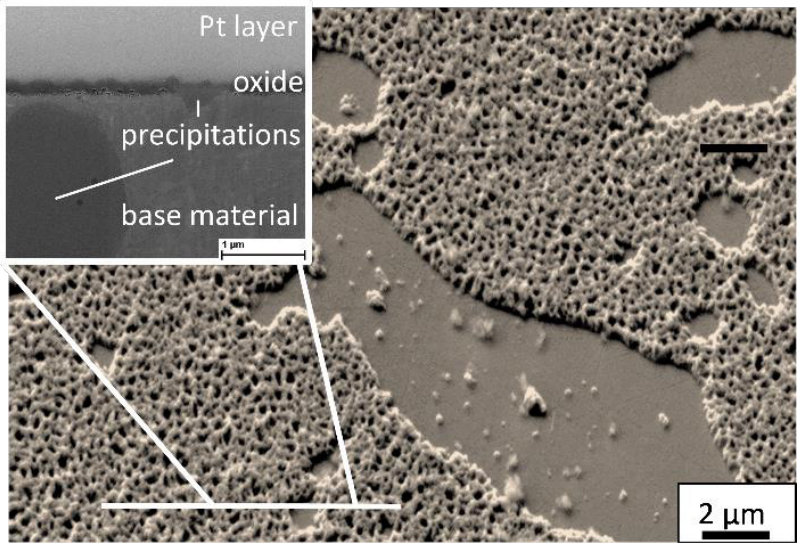

Fig. 7. SEM micrograph of convectively heat treated oxide layer formed along with a cross sectional secondary electron image in the inset

\subsection{Measurement of hardness}

Hardness measurements were performed along cross sectional areas of the tempered specimen in order to determine the effect of different peak temperatures above the annealing temperature on the mechanical properties of the tool steel. Figure 8 present hardness data measured on the specimen in direction from the specimen surface to the centre. Clearly, tempering procedures with short initial temperatures between $570{ }^{\circ} \mathrm{C}$ (specimen $\mathrm{B} 1$ ) and $620^{\circ} \mathrm{C}$ (specimen B2) have negligible influences on the material, while a heat treatment up to $700{ }^{\circ} \mathrm{C}$ decreases the HV30 value by nearly $40 \%$ (Specimen B4) .

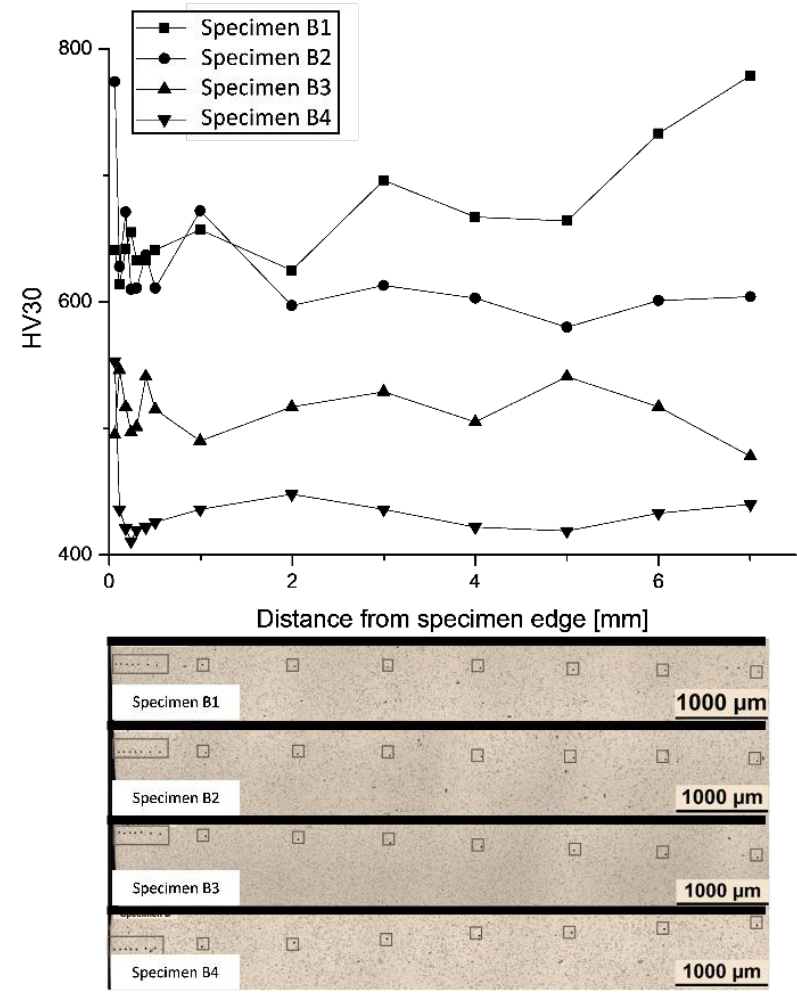

Fig. 8. Hardness profile of cross sections of inductively tempered specimens

\subsection{Surface analysis after wear}

The wear investigations were performed at constant loading conditions at $80^{\circ} \mathrm{C}$ specimen temperature and a normal stress of $80 \mathrm{MPa}$. Selected specimens that have kept a HV30 value within the scope of tolerance after the hardening procedure were tested with 500 strokes. Therefore, specimen B1 (initial temperature: $570{ }^{\circ} \mathrm{C}$ ) and specimen $\mathrm{B} 2\left(620^{\circ} \mathrm{C}\right)$, which seem to have no noticeable losses of hardness after the tempering process were characterized regarding their sliding wear resistance in comparison to conventional heat treated (A1) and the reference specimen (R1).

The surface topography of the specimen was measured before and after the wear investigations in order to characterize the morphological changes of the surfaces. For this purpose, the arithmetical mean height $S_{\mathrm{A}}$ and the dale void volume $V_{\mathrm{Vv}}$ measurements were determined in the area at the central $45^{\circ}$ position of the specimen prior and after the wear investigations. This position represents a constant normal stress loading case, while the contact area of the tool steel and the drawn sheet metal amounts to $\pi / 2$ of the specimen surface. In Fig. 9 the arithmetical mean height $S_{\mathrm{A}}$ for different specimens before and after the wear investigation are compared. In general, selectively oxidized surfaces seem to feature smaller initial $S_{\mathrm{A}}$-values than untreated reference samples before wear testing. Furthermore, the convectively tempered specimen A1 shows the lowest initial arithmetical mean height. Clearly, the magnitude of reduction in the $S_{\mathrm{A}^{-}}$ values after wear testing is nearly constant (at about $10 \%$ ) for selectively oxidized specimen, while the reference sample R1 exhibits a loss of nearly $30 \%$. Thus, the arithmetical mean height of the oxidized specimens is not significantly changing during wear, but even appears to decrease slightly. The clear decrease of the $S_{\mathrm{A}}$-value of the reference specimen R1 after the wear tests could be related to two mechanisms that seem to govern the wear process. As a major effect, smoothening of the surface appears. Secondly, transferred zinc coating from the sheet metal can result in adhesive zinc pick-up, which was also observed in previous studies [8]. This is confirmed by analyzing the dale void volume $V_{\mathrm{vv}}$, which is a parameter that provides information about the empty volume of surface valleys. In Fig. 10 the dale void volumes determined prior to and after the wear tests for each specimen are given. The dale void volume $V_{\mathrm{Vv}}$ shows a trend that can be related with the arithmetical mean height. Following wear, $V_{\mathrm{VV}}$ decreases substantially for the reference surfaces, whereas only small changes were obtained for the oxidized surfaces. The friction coefficient decreased slightly for the selectively oxidized specimen compared to the virgin reference. Furthermore, the inductively tempered specimen showed lower friction coefficients than convectively tempered specimen. As a result an increasing effect of thicker oxide systems as friction reducing separation layers occurs. 


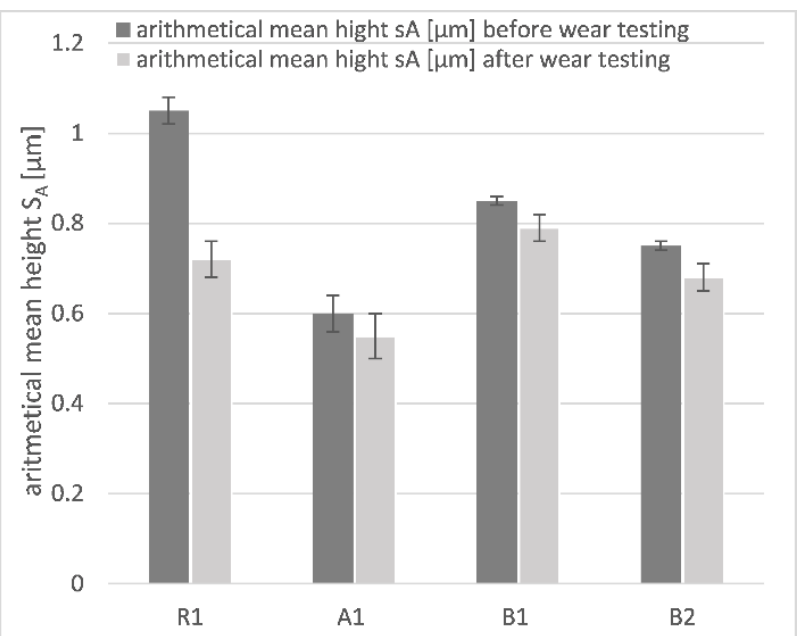

Fig. 9. Arithmetical mean height $S_{\mathrm{A}}$ prior to (dark grey) and after (grey) wear tests for each type of specimen

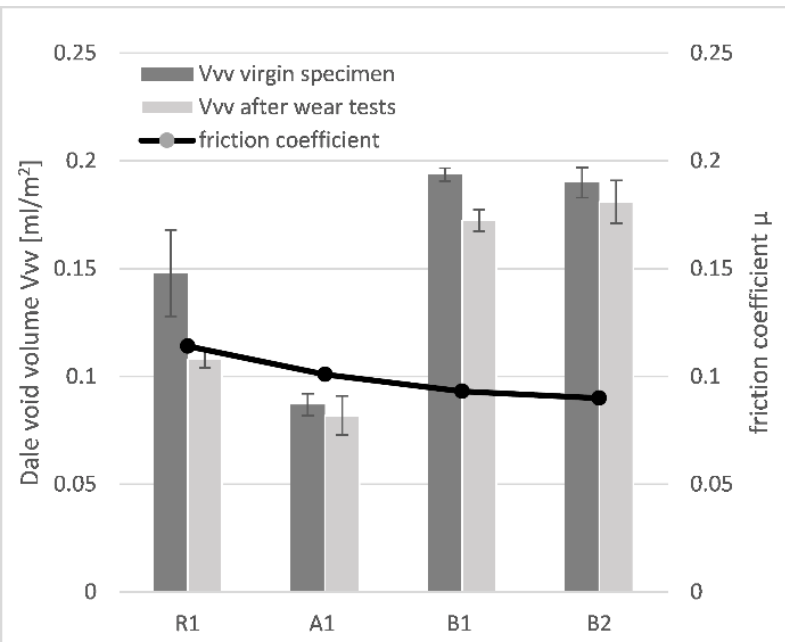

Fig. 10. Dale void volume $V_{\mathrm{Vv}}$ and friction coefficient prior to (dark grey) and after (grey) wear tests for each type of specimen

To gain further insight into the wear mechanisms, SEM micrographs of the specimen B1 and specimen B2 were taken prior to and after the wear tests. For condition B1, an untested specimen is shown in Fig. 11 (top) along with a SE image of the critical $45^{\circ}$ area in a tested one. The surface is completely covered, with a chain-like bonding oxide structure, which is characteristic for $\alpha-\mathrm{Fe}_{2} \mathrm{O}_{3}$ layer systems. After the wear tests, the layer appears smoothed (Fig. 11 bottom). The SE micrograph shown in Fig. 11 was recorded at the central position of the worn area. The layer structure is still recognizable and the chain-like oxide bondings are even more concentrated, and oxide particles seem to have been picked up during the wear tests at uncovered substrate areas.

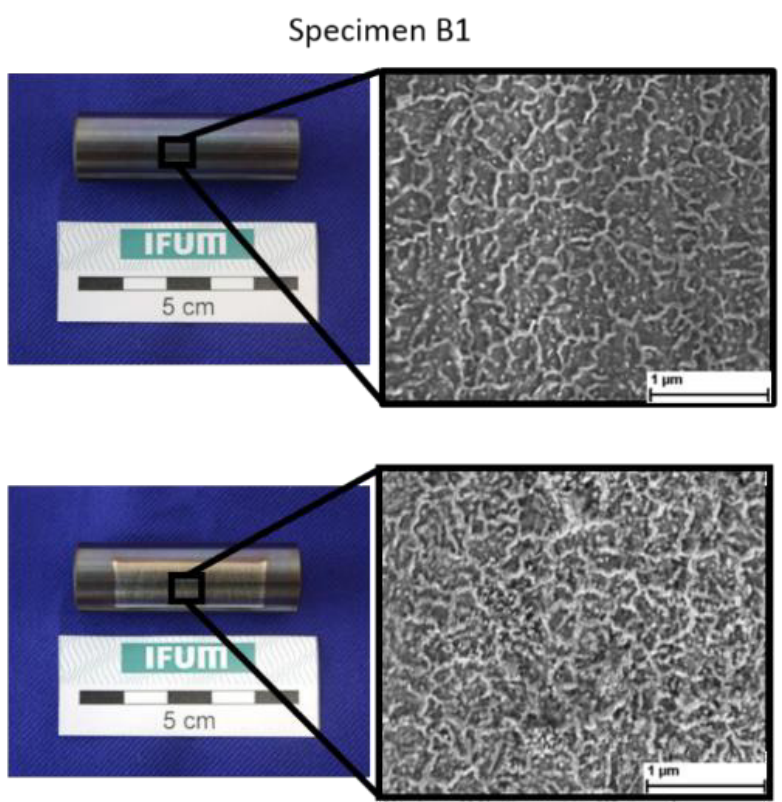

Fig. 11. Specimen B1 prior to (top) and after (bottom) the wear test (500 strokes); SE images were taken a low acceleration voltage of $3 \mathrm{kV}$ to minimise charging effects

This effect was also confirmed for specimen B2. The micrograph (Fig. 12 top) also showed a layer system with a similar structure of chain-like oxide bondings prior to the wear tests, but the occurrence is more intense. Again small particles have accumulated in between the chain structure of the oxide compounds after the wear test (Fig. 12 bottom).

\section{Specimen B2}
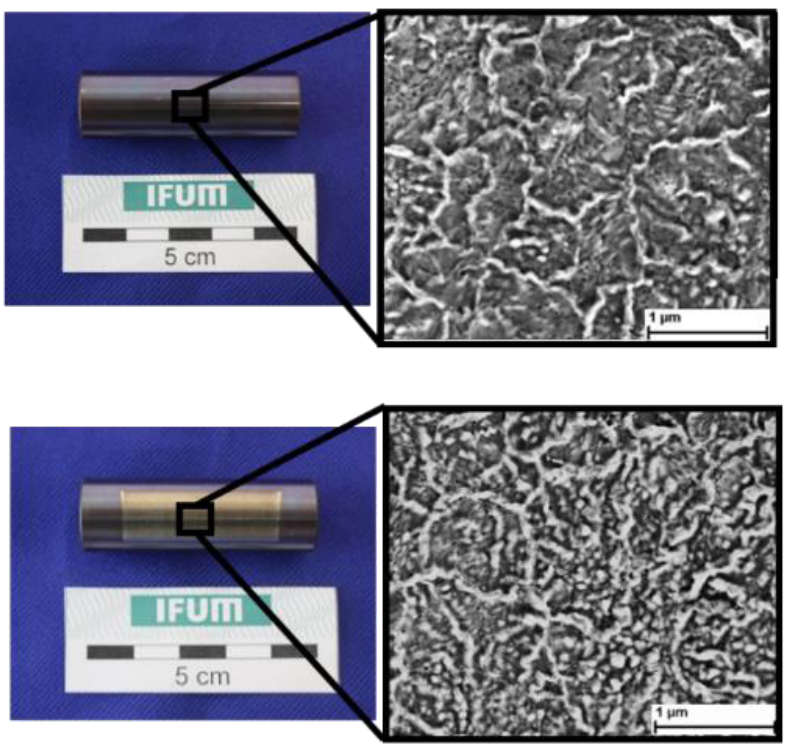

Fig. 12. Wear specimen B2 prior to (top) and after (bottom) the wear tests (500 strokes); SE images were taken at $3 \mathrm{kV}$ 


\section{Discussion and outlook}

Depending on the actual heat treatment parameters, the oxide layer systems generated inductively at higher peak temperatures showed substantially different behaviour. On the one hand, peak temperatures above the annealing temperature of the tool steel can favour surface activation, and thus, selective oxidation processes that are caused by thermal acceleration of diffusion and higher reactivity of the tool steel elements with oxygen. On the other hand, even short dwell periods at peak temperatures above $620{ }^{\circ} \mathrm{C}$ reduced the hardness of the tool steel by nearly $40 \%$ in the bulk. In this context, it is important to note that the hardened tool steel features precipitations of chromium carbides, which also occur in the near surface areas. The focussed ion-beam prepared cross sections of the inductively tempered reference specimen showed that the carbides correspond to the areas that were not covered by the $\alpha-\mathrm{Fe}_{2} \mathrm{O}_{3}$ oxide layer. As this may negatively affect the long-term wear behaviour, powder metallurgically manufactured tool steel with fewer or smaller chromium carbides might provide for even better performance in this respect. This approach is based on the assumption that layer defects increase constantly as a function of wear.

The measured arithmetical mean height and dale void volume of inductively tempered specimen indicated promising wear behaviour. Decreasing arithmetical mean height and dale void volume were determined after the wear tests and SEM micrographs also showed a characteristic oxide structure with several particle pickups in between the oxide compounds. It is assumed that these result from tribooxidation effects. Increased surface temperatures at the contact areas between tool steel and drawn sheet metal should favour oxide growth. Thus, it appears feasible that an erosion of the oxide layer might be counterbalanced by a growth of oxide particles.

The present study demonstrates that inductive heat treatment could be a viable approach generating reproducible oxide layer systems by selective oxidation processes. Compared to conventional heat treatments, the higher heating rates in combination with short isothermal dwell periods would reduce overall processing times. More importantly, however, the hardness of the bulk is less affected by this approach. Albeit the current study indicated promising wear properties, it should be noted that the contact pressures in industrial deep drawing processes could be substantially higher than those used in the present set-up for measuring sliding wear resistance, and work is underway to address this effect.

\section{Acknowledgements}

Financial support of this study by the German Research Foundation (DFG) (reference numbers BE1690/170-2 and MA1175/41-2) within the framework of the priority programme Sustainable Production through Dry Processing in Metal Forming (SPP 1676) is gratefully acknowledged.

\section{References}

[1] B.-A. Behrens, A. Bouguecha, B. Homan, Investigations of surface topography evolution of sheet aluminum under pressure and tension, Comput. Plast. XII (2013) 1230-1237.

[2] G. Braeuer, H. Paschke, M. Weber, B.-A. Behrens, T. Yilkiran, Surface modifications for optimized forming operations, Key Eng. Mater. 611-612 (2014) 231-239, http://dx.doi.org/10.4028/www.scientific.net/KEM.6 11-612.231.

[3] B.-A. Behrens, A. Bouguecha, L. Lüken, J. Mielke, M. Biston, Tribology in hot forging, Compr. Mater. Process. 5 (2014) 211-234, http://dx.doi.org/10.1016/B978-0-08-096532$\underline{1.00538-0 .}$.

[4] J. Glascott, F. H. Stott, G. C. Wood, The effectiveness of oxides in reducing sliding wear of alloys, Oxid. Met. 24 (1985) 99-113, http://dx.doi.org/10.1007/BF00664227.

[5] J. Glascott, G. C. Wood, F. H. Stott, The influence of experimental variables on the development and maintenance of wear-protective oxides during sliding of high-temperature iron-base alloys. Proc. Inst. Mech. 199 (1985) 43-41, http://dx.doi.org/10.1243/PIME_PROC $1985 \quad 199 \quad 0$ $\underline{8802}$.

[6] F.H. Stott, M. P. Jordan, The effects of load and substrate hardness on the development and maintenance of wear-protective layers during sliding at elevated temperatures, Wear 250 (2001) 391-400, http://dx.doi.org/10.1016/S0043-1648(01)00601-9.

[7] D. Yilkiran, A. Almohallami, D. Wulff, S. Hübner, M. Vucetic, H. J. Maier, B.-A. Behrens: New Specimen Design for Wear In-vestigations in Dry Sheet Metal Forming, Dry Met. Forming OAJ FMT 2 (2016) 62-66.

[8] D. Yilkiran, D. Wulff, A. Almohallami, F. Özkaya, A. Bouguecha, S. Hübner, K. Möhwald, H. J. Maier, B.-A. Behrens, Wear behaviour of thermally oxidized tool surfaces as low-friction separation layers for dry sheet metal forming, Wear Vol. 376 - 377 (2017) 